\title{
OP05
}

\section{AN INITIAL STUDY OF COLOUR APPEARANCE IN VIRTUAL REALITY}

\author{
Chi Han Ma et al.
}

DOI 10.25039/x46.2019.OP05

from

CIE x046:2019

\section{Proceedings}

of the

29th CIE SESSION

Washington D.C., USA, June 14 - 22, 2019

(DOI 10.25039/x46.2019)

The paper has been presented at the 29th CIE Session, Washington D.C., USA, June 14-22, 2019. It has not been peer-reviewed by CIE.

\section{(C) CIE 2019}

All rights reserved. Unless otherwise specified, no part of this publication may be reproduced or utilized in any form or by any means, electronic or mechanical, including photocopying and microfilm, without permission in writing from CIE Central Bureau at the address below. Any mention of organizations or products does not imply endorsement by the CIE.

This paper is made available open access for individual use. However, in all other cases all rights are reserved unless explicit permission is sought from and given by the CIE.

CIE Central Bureau

Babenbergerstrasse 9

A-1010 Vienna

Austria

Tel.: +43 17143187

e-mail: ciecb@cie.co.at

www.cie.co.at 


\title{
AN INITIAL STUDY OF COLOUR APPEARANCE IN VIRTUAL REALITY
}

\author{
$\mathrm{Ma}, \mathrm{C} ., \mathrm{Ou}, \mathrm{L}$. \\ National Taiwan University of Science and Technology, Taipei, CHINESE TAIPEI \\ karena6041@gmail.com
}

DOI $10.25039 / \times 46.2019 .0 P 05$

\begin{abstract}
This study aimed to investigate colour appearance in virtual reality (VR). A total of 35 test colours were visually assessed in a VR space by 16 observers in terms of lightness, colourfulness and hue quadrature. The experimental results show high correlation between perceived colour appearance and predicted values by CIECAM02, with a correlation coefficient of 0.96 between perceived lightness and CIECAM02 J, 0.99 between perceived hue quadrature and CIECAM02 $\mathrm{H}$, and 0.88 between perceived colourfulness and CIECAM02 M.
\end{abstract}

Keywords: Colour appearance, Virtual reality, CIECAM02

\section{Introduction}

Virtual reality (VR) has been prevalent in recent years, and you can imagine there will be more and more applications based on VR technology in the future. Due to the popularity of this technology, there is an increasing demand for understanding of colour appearance in a VR environment. By designing a VR space for visual assessment of colour appearance, we were able to investigate the appearance of colour in VR. We also looked into the difference in colour appearance between VR and real-world experience by comparing the experimental results with predictive values by CIECAM02 (Moroney et al., 2002). The findings of the study may help develop new models of colour appearance for VR applications.

\section{Methods}

To achieve this aim, a psychophysical experiment of colour appearance was conducted using a mobile VR headset, and a VR space was created using the 3DS MAX software in which the appearance of colour patches shown in the VR space were visually assessed.

The mobile VR headset used in this experiment was Miniso Simple 3D VR Glasses, with a viewing angle of up to 90 degrees and a spherical lens diameter of $40 \mathrm{~mm}$. An iPhone 6 , with a 4.7 -inch screen that had a resolution of 1334 by 750 pixels, i.e. $326 \mathrm{ppi}$, was used to present the VR images.

\subsection{VR Space}

The VR space was 220 (width) by 255 (depth) by 200 (height) in size. All walls, ceiling and floor in this space were coloured medium grey. On the main wall, which the observer was naturally facing, were 3 colour patches presented side by side, all of which were lit uniformly by a virtual wall washer as the white light source. The layout for the experiment is shown in Figure 1. The left colour patch was the reference white, with an adopted lightness value of 100 . The one on the right was the reference colourfulness, with an adopted colourfulness value of 23 . The colour patch in the middle was the test colour, with a perceived size of 37.50 by $37.50 \mathrm{~cm}$, which was larger than the two reference colour patches, both having a perceived size of 21.25 by $21.25 \mathrm{~cm}$. The reference white had a luminance of $200.16 \mathrm{~cd} / \mathrm{m}^{2}$, with $(x, y)=(0.308,0.324)$. The viewing distance for the main wall was perceived to be $214.38 \mathrm{~cm}$. This indicates that the test colour had a perceived viewing angle of 10 degrees. Note that all the perceived size and distance values in this VR space were determined by visual comparisons between the VR and a realworld space using magnitude estimation method. 


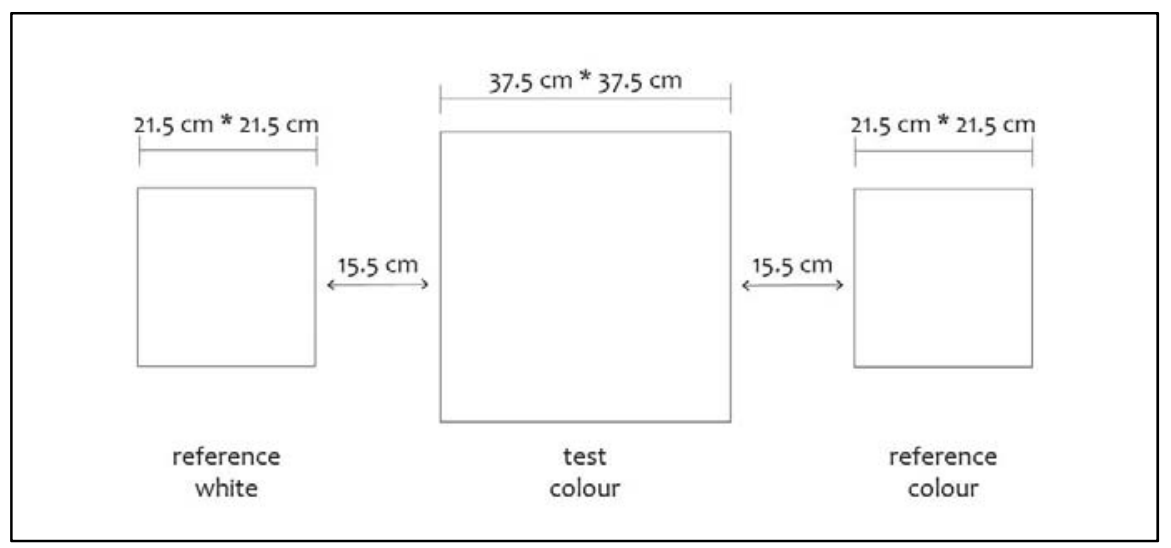

Figure 1 - The layout for visual assessment of colour appearance in this study

\subsection{Colour Samples}

The experiment used 35 test colours, selected from CIELAB space to cover a wide variety of hue, lightness and chroma. The test colours of this experiment are plotted in CIELAB $a^{*}-b^{*}, L^{*}-$ $a^{*}$ and $L^{*}-b^{*}$ space in Figure 2. The colours consisted of 5 hue regions, red (with a hue angle of $\left.20^{\circ}\right)$, yellow $\left(90^{\circ}\right)$, green $\left(164^{\circ}\right)$, blue $\left(245^{\circ}\right)$ and purple $\left(320^{\circ}\right)$, each containing three levels of lightness, 25, 50 and 75, and two levels of chroma, 15 and 30 . This resulted in 5 hue regions x 3 lightness $\times 2$ chroma +5 achromatic colours $=35$ test colours in total. There were 10 test colours replicated, and thus each observer made 45 visual assessments in the VR space.

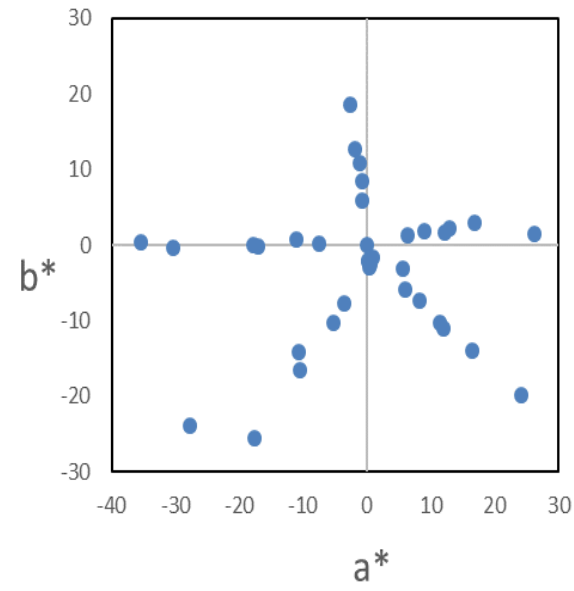

(a)

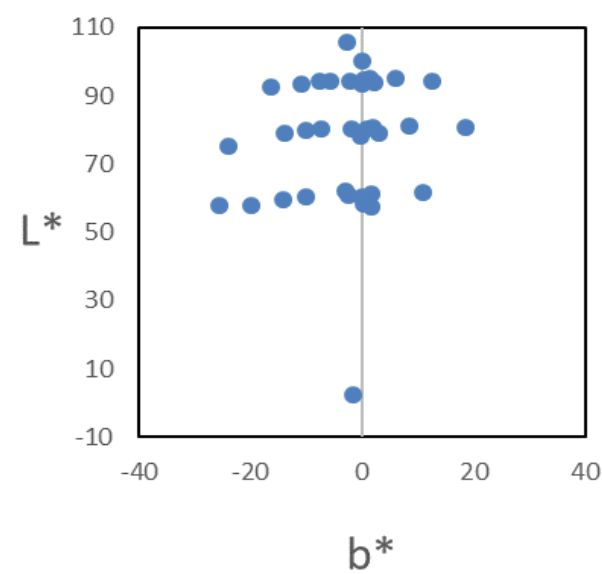

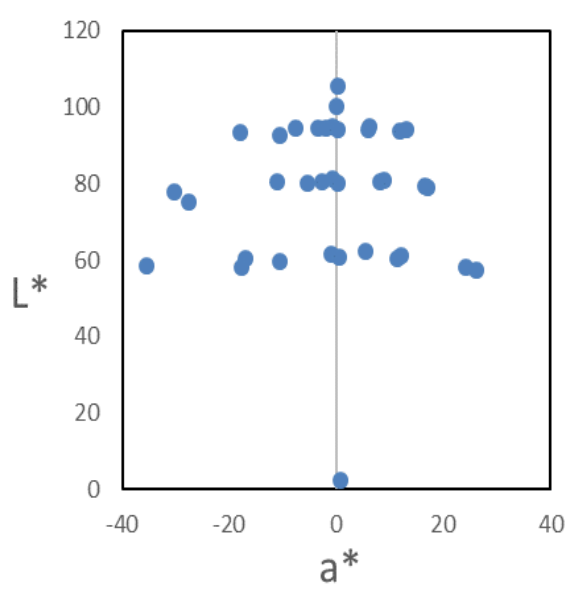

(b)

(c)

Figure 2 - The test colours in (a) CIELAB $a^{*}-b^{*}$, (b) CIELAB $L^{*}-a^{*}$ and (c) CIELAB $L^{*}-b^{*}$ planes. 


\subsection{Experimental Procedure}

During the experiment, the observer was asked to assess each test colour in terms of lightness, colourfulness and hue quadrature using magnitude estimation method. The test colours were presented one at a time in random order. Note that for each observer the entire experiment lasted about 40 minutes, during which the observer needed to wear the VR headset to perform the visual assessments. Thus, there was a 10-minute break for each observer after completing 25 test colours, and during the break the observer was encouraged to take off the VR headset to get a rest.

A panel of 16 observers, all university students with normal colour vision, participated in the study. None of the observers reported visual discomfort after the experiment.

\section{Results}

To see whether there was any difference in colour appearance between the VR space and the real-world environment, visual results obtained in this study were compared with the predicted values by CIECAM02 in terms of lightness, colourfulness and hue quadrature.

As a result, high correlation was found between perceived lightness and CIECAM02 J, with a correlation coefficient of 0.96 . High correlation was also found between perceived hue quadrature and CIECAM02 $\mathrm{H}$, with a correlation coefficient of 0.99 . The results indicate high consistency in colour appearance between the VR space and the real-world environment in terms of lightness and hue.

Nevertheless, correlation between perceived colourfulness and CIECAM02 M was 0.88, a relatively lower value than those for the other two scales of colour appearance. The scatter graph of perceived colourfulness (at vertical axis) against CIECAM02 M (at horizontal axis) shows a somewhat logarithmic curve.

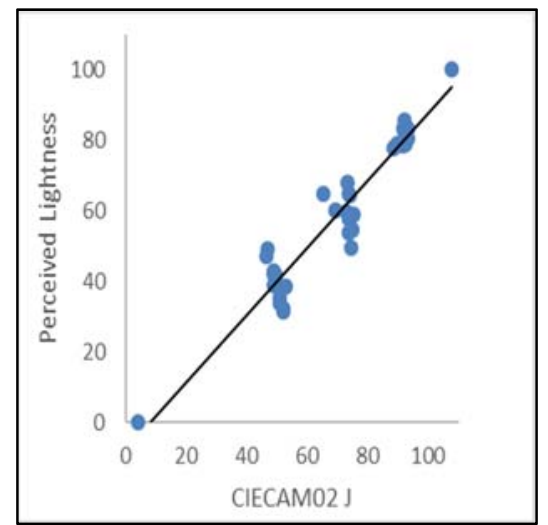

(a)

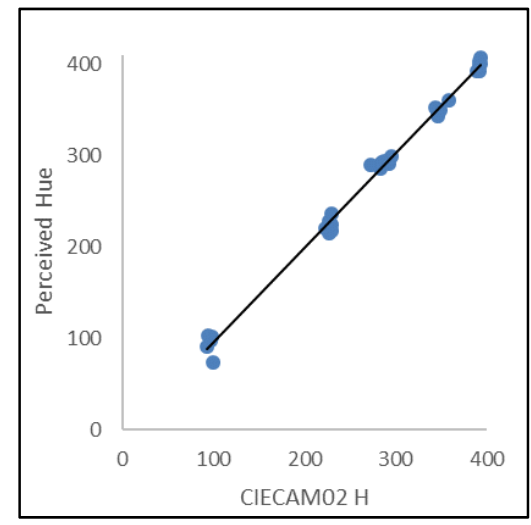

(c)

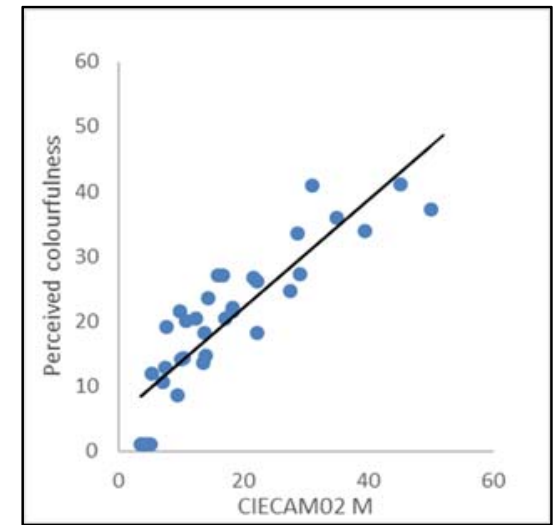

(b)

Figure 3 - Comparisons between perceived colour appearance and CIECAM02 values in terms of (a) lightness, (b) colourfulness and (c) hue quadrature. 


\section{Conclusions}

According to the experimental results, lightness and hue both show high consistency between the VR space and the real-world environment, the latter being represented by CIECAM02 $\mathrm{J}$ and $H$ values. Colourfulness was the only scale that shows a non-linear relationship between the VR space and the real-world environment.

As an initial attempt to study colour appearance in VR, it is unclear whether the findings described above truly reflect colour appearance phenomena in VR, or there might be other factors that have affected the experimental results. First, all colours in this study were measured using a Topcon SR-UL1R spectroradiometer, without considering the fact that the lens design of the spectroradiometer may not provide the best solution for measuring near-eye displays. Second, this study used a reference colourfulness of 23 . Some observers complained that this value was too low for them as a reference when estimating perceived colourfulness for greyish colours. How to select the right colour as the reference colourfulness may be the key here. All these issues will need to be investigated further in future studies.

\section{References}

Moroney, N., Fairchild, M.D., Hunt, R.W., Li, C., Luo, M.R. and Newman, T., 2002, January. The CIECAM02 color appearance model. In Color and Imaging Conference (Vol. 2002, No. 1, pp. 23-27). Society for Imaging Science and Technology. 